\title{
Estudios visuales y estilo televisivo: porque no existen medios puramente visuales
}

Visual studies and television style: because there are no purely visual media

Estudos visuais e estilo de televisão: porque não existem meios puramente visuais

Simone Maria ROCHA

Universidade Federal de Minas Gerais, Brasil / rochasimonemaria@gmail.com

Chasqui. Revista Latinoamericana de Comunicación

N.o 135, agosto-noviembre 2017 (Sección Ensayo, pp. 297-316)

ISSN 1390-1079 / e-ISSN 1390-924X

Ecuador: CIESPAL

Recibido: 15-o9-2016 / Aprobado: 10-05-2017 


\title{
Resumen
}

Este artículo presenta una propuesta de análisis de productos televisuales que operan en la disyunción de las dimensiones formales y culturales de este medio. Tal propósito implica tener en consideración la complejidad de la televisión, su reconocido valor cultural y la especificidad de sus productos. Para ello, tomamos como noción teórico-metodológica central el concepto de visualidad, del modo en que es presentado por la perspectiva de los visual studies.

Palabras clave: análisis televisual; televisualidad; visual studies.

\begin{abstract}
This paper presents an analysis proposal for televisual products that works in non-dissociation of this medium's formal and cultural dimensions. Such effort implies taking into account the complexity of television, its recognized cultural value and specificity of its products. Therefore, we adopt the theoretical and methodological central notion of visuality such as presented by the visual studies perspective.
\end{abstract}

Keywords: televisual analysis; televisuality; visual studies.

\section{Resumo}

Este artigo apresenta uma proposta de análise de produtos televisuais que opera na não disjunção das dimensões formais e culturais deste meio. Tal empreendimento implica levar em conta a complexidade da televisão, seu reconhecido valor cultural e a especificidade de seus produtos. Para tanto, tomamos como noção teórico-metodológica o conceito de visualidade tal como apresentado pela perspectiva dos visual studies.

Palavras-chave: análise televisual; televisualidade; visual studies. 


\section{Cultura visual, la noción teórico-metodológica de visualidad y la inclusión de productos televisivos ${ }^{1}$}

Este texto pretende presentar una propuesta que consiga proceder con un análisis de productos televisivos que articule sus dimensiones cultural y formal sin perder de vista la complejidad del propio medium, así como sus peculiaridades. El desarrollo de tecnologías específicas, sobre todo la implementación de la televisión digital y popularización de aparatos con alta definición (HD), comenzó a permitir un incremento en la calidad técnica e innovaciones en el estilo televisivo, acarreando modificaciones tanto en la dimensión audiovisual de los productos como en sus estrategias comunicativas. A partir de tales cambios surgió la preocupación por entender cómo la televisión también cuenta sus historias a través de la experiencia visual que ella proporciona. Además, figura entre nuestros principales objetivos comprender cómo tal experiencia está atravesada por el contexto al cual pertenecen las narrativas y revelar los aspectos culturales, políticos e históricos que sirven de base a las historias contadas.

Tal preocupación nos condujo al encuentro de la propuesta de los estudios de la cultura visual, principalmente, el abordaje desarrollado por William J. Thomas Mitchell y Hall Foster. Considerados un proyecto interdisciplinar, que surgió en la década de 1980 como alternativa a un conjunto de disciplinas académicas -como la historia del arte-, tales estudios proponen un desplazamiento del concepto de historia hacia el de cultura y del de arte hacia el de visual y se centran en el entendimiento de las diferentes manifestaciones históricas de toda experiencia visual, o sea, de la visualidad. No podemos considerar tal experiencia, independientemente de que sea valorada o no como arte, como una ventana transparente para lo real, si tenemos en cuenta la variedad de prácticas y de contextos culturales en los cuales ella ocurre. Eso nos permite decir que una experiencia visual no es natural/universal, como si fuese la misma para todos independientemente del contexto histórico.

La cultura permea nuestra experiencia visual de diferentes modos, de los más evidentes a los más sutiles. Pablo Sérvio (2014) apunta que nuestro cerebro tiene una capacidad limitada para procesar las informaciones que le son enviadas por los ojos, conduciéndonos a una percepción selectiva. El autor destaca en este proceso la dimensión cultural como aquella que, en gran medida, orienta nuestra atención hacia determinadas cosas, eventos o personas. ${ }^{2}$ Para el autor,

1 Agradezco al CNPq y a la Fapemig la ayuda financiera.

2 Sérvio menciona el ejemplo de los recolectores de basura, estudiado por Fernando Braga (2004), considerados "hombres invisibles" cuando visten sus uniformes de trabajo colorido. Los recolectores relatan que, a partir de ese momento, se vuelven invisibles para los que pasan cerca de ellos en la calle. Sérvio parte de ese ejemplo para argumentar que la percepción selectiva no sería lo suficiente para entender esa situación. Su comprensión demanda el escrutinio del contexto en el cual el uso de ciertas ropas relega a sus usuarios a la invisibilidad. 
La percepción selectiva es construida de manera táctica, a partir de rutinas, de preferencias y de prácticas de mirar que se estructuran y ganan organicidad interna sin que nos demos cuenta. Ella se desarrolla de manera inconsciente, influenciada por prácticas culturales, por estímulos externos y/o internos sobre los cuales no tenemos control (Sérvio, 2014, p. 199.)

Además, Mitchell afirma que no existen medios puramente visuales. Para él "todas las artes 'son compuestas' (tanto el texto como la imagen); todos los medios son mixtos, combinan diferentes códigos, convenciones discursivas, canales y modos sensoriales y cognitivos" (Mitchell, 2009, p. 88). Y, para sustentar tal afirmación, el autor introduce la figura de imagen/texto ${ }^{3}$ como un instrumento con el cual podemos abrir la heterogeneidad de los medios y de sus representaciones específicas. Tratar una imagen/texto no es detenerse solamente en la descripción formal, sino también interrogarse por la función de las formas específicas de heterogeneidad.

En síntesis, el objetivo de una investigación en cultura visual es investigar la interacción entre las representaciones visuales y verbales, o las relaciones imagen/texto, en una variedad de medios y articularlas en torno a las cuestiones relativas al poder, al valor y al interés humano, histórico y social. Para Knauss (2006, p. 112) "el estudio de la cultura visual debe tratar de objetos capturados en la red de significados culturales, buscando escapar del presentismo que envuelve los valores artísticos".

Así, hablar de determinaciones culturales de la experiencia visual parece incongruente con centrarse exclusivamente en las imágenes. La visualidad trata de esa experiencia como un todo. José Luis Brea (2005) argumenta que ella es producto de un trenzado de elementos textuales, mentales, imaginarios, mnemónicos, mediáticos, técnicos, burocráticos, institucionales y ciertos propósitos (políticamente orientados).

La apertura traída por la llegada de los estudios de la cultura visual es significativa en virtud de la gama de objetos que abarca, incluyendo el de las materialidades televisivas -comúnmente ignoradas y subestimadas en su dimensión audiovisual-. Para Barnard (2001, pp. 1-2), estos estudios van desde "el campo de las bellas artes o artes canónicas, como el design, el cine, la fotografía, la publicidad, el vídeo, la televisión o internet”. En ese sentido, la cultura visual permite el escrutinio de este medio en una clave de lectura en positivo, es decir, lo que son, cómo se constituyen, se configuran, cómo se relacionan con la esfera cultural desde su dimensión formal. Además, las proposiciones de los estudios

3 El autor utiliza la convención tipográfica de la barra diagonal para designar la "imagen/texto" como una brecha, una fisura o ruptura problemática en la representación. Mitchell se inspira en Foucault cuando de su análisis sobre el cuadro Las Meninas afirma que "la relación del lenguaje con la pintura es una relación infinita". Además, esclarece que "el término 'imagentexto' designa obras (o conceptos) compuestos, sintéticos, que combinan el texto y la imagen. 'Imagen-texto', con un guion, designa relaciones entre lo visual y lo verbal”. Cf. Mitchell, 2009, p. 84. 
de la cultura visual ayudan a superar la dicotomía "arte elevado" versus "arte rebajado", ya que la historia de las imágenes inspira cierta democratización de las mismas, así como elige la perspectiva interdisciplinaria como un encuentro igual de necesario cuando se trata de pensar lo visual.

\section{Televisualidad}

Del concepto de visualidad derivamos el de televisualidad, o sea, de las determinaciones culturales de la experiencia visual en productos televisuales. Mitchell asegura que el medio televisivo, como el cine y las performances teatrales, presenta:

Conjunciones reales de palabras e imágenes [...]. En estos medios nos encontramos con un conjunto concreto dado, una estructura de imagen/texto que puede responder a las convenciones dominantes (o a la resistencia a la convención) que gobiernan la relación de la experiencia visual y la verbal (2009, p. 85.)

Por lo tanto, hablar de televisualidad es tener en cuenta que la TV posee regímenes de visualidad que se configuran si se consideran las características materiales e inmateriales del dispositivo. Destacamos la relevancia de esta noción, pues la misma nos orienta en la percepción de los modos en que los textos muestran las cuestiones tejidas y vividas en el terreno de la política y de la cultura.

\section{Cuestiones metodológicas}

Lo que Mitchell propone está basado en un entendimiento pos-lingüístico de la imagen, ${ }^{4}$ lo que nos indica, en palabras de Paulo Knauss (2006, p. 113), que "hay, así, una relación entre visión y contexto que precisa ser establecida”.

Mitchell advierte que es fundamental la relación que el investigador establecerá con las imágenes, pues antes de enredarse con cuestiones de significado, él deberá comprender, aunque en un sentido figurado, que estas necesitan ser

4 El abordaje de Mitchell está basado en lo que él denominó como giro pictórico (pictorical turn), cuya propuesta se vuelca para un "redescubrimiento pos-lingüístico de la imagen" como un "punto singular de fricción y desasosiego que atraviesa transversalmente una gran variedad de campos de investigación intelectual. La imagen ha adquirido un carácter que se sitúa a mitad de camino entre lo que Thomas Kuhn llamó un "paradigma" y una "anomalía", apareciendo como un tema de debate fundamental en las ciencias humanas, del mismo modo que ya lo hizo el lenguaje: es decir, como un modelo o figura de otras cosas (incluyendo la figuración misma) y como un problema por resolver, quizá incluso como el objeto de su propia "ciencia", lo que Erwin Panofsky llamó "iconología”. Para Mitchell no se trata de sobreponer lo visual a lo verbal como una especie de inversión de lo que él juzga que es la propuesta del giro lingüístico, sino de entender las interacciones entre las representaciones visuales y verbales y sus relaciones con las cuestiones culturales más amplias. Para este autor, su propuesta "pretende ser nada menos que una iconología crítica, un recuento autoteorizante de la cultura visual” (Cf. Mitchell, [1994] 2009, p. 21 y 29). 
vistas como seres animados que pueden tener la pretensión de decir algo. ${ }^{5}$ Alejarse de las cuestiones de significado y del poder no expresa un abandono de los procedimientos de la semiótica, la hermenéutica y la retórica. La cuestión de lo que las imágenes quieren no elimina la interpretación de los signos, al final la experiencia visual no se realiza de modo aislado y es enriquecida por las memorias, imágenes e imaginarios de varios universos de nuestras vidas. Lo que sucede es un desplazamiento sutil del centro de interpretación para conferirle a las imágenes un lugar "intermediario" en las transacciones sociales, como un repertorio o una especie de modelo que dice mucho de nuestra dinámica social. En otras palabras, si la imagen llega a convertirse en algo natural o familiar, y ahí reside la experiencia de la visión, Mitchell llama la atención hacia un necesario gesto de revolver, sacudir el terreno, de manera que se convierta en un problema susceptible de ser analizado, una vez que la visión es una construcción cultural que es tanto aprendida como cultivada.

Aunque los estudios de la cultura visual propongan un gesto renovado en el modo de abordar las imágenes, no identificamos ninguna propuesta metodológica que viabilice el análisis de los productos televisuales de diferentes géneros y formatos. La imagen/texto no es ni un método ni una garantía de descubrimientos históricos; debe ser vista más como una abertura en la representación, un lugar donde la historia puede deslizarse a través de las fisuras entre el discurso y la representación visual. Persiste, así, el desafío de captar la historia y el tejido espeso de la cultura que sutura las relaciones imagen/texto.

\section{El análisis de estilo televisivo}

Al pensar en una solución que viabilizase la propuesta de análisis de los productos, teniendo como base la noción de televisualidad, decidimos apostar por la articulación de esta noción con un análisis formal del estilo televisivo, evidenciando su capacidad para abordar los productos y sus entrelazamientos contextuales.

De la relación imagen/sonido (¿o sería imagen/texto?) la televisión deriva su estilo. Jeremy Butler defiende una definición de estilo como cualquier patrón técnico de imagen/sonido que tenga una función propia dentro del texto televisivo. De ese modo, podemos concluir que todos los textos televisivos contienen estilo. Para Butler "estilo es su estructura, su superficie, la red que mantiene juntos sus significantes y a través del cual sus significados son comunicados” (2010, p. 15).

5 En sus principales obras como Iconology y Teoría de la Imagen, Mitchell deja claro que no hay una teoría de la imagen satisfactoria y que entenderla a través de una teoría ya sería colocarla en el orden del discurso. En realidad, al defender que la experiencia visual y la verbal están entrelazadas, inextricablemente imbricadas, el autor ya plantea la imposibilidad de una meta-lingüística estricta. El autor afirma que su objetivo no es exactamente decir lo que son las imágenes, sino lo que ellas hacen, lo que ellas dicen, puesto que ellas quieren decir algo. Podemos decir que Mitchell considera la imagen como representación en el sentido de "estar en lugar o actuar por" (Cf. Mitchell, [1994] 2009). 
La inspiración de Butler viene de David Bordwell, un estudioso de la historia del estilo en el cine que estableció que la poética se refiere al estudio acerca de cómo los filmes son agrupados y cómo, en contextos determinados, provocan efectos particulares. Jeremy Butler se basa en la concepción de David Bordwell, para quien:

El estilo en cine importa porque lo que las personas llaman el contenido llega hasta nosotros a través de la utilización estandarizada de técnicas del medio... Estilo es la textura tangible de un filme, la superficie perceptual que nosotros encontramos mientras vemos y oímos, y esta superficie es nuestro punto de partida en el desarrollo de la trama, del tema y del sentimiento -todo lo que nos importa. (Bordwell, 2008, p.32)

El estilo puede ser visto como la manifestación física del tema y de la narrativa, elementos que están siempre situados culturalmente. Por eso, Butler interroga el poder significante del sonido y de la imagen en la televisión. Tal noción de estilo y su propuesta metodológica abren el texto a lo que Mitchell llama "entendimiento pos-lingüístico de la imagen". El nivel de observación exigido por un análisis formal despierta la atención del investigador hacia ciertos modos de mostrar, cuyas especificidades van más allá de elecciones formales.

La articulación entre televisualidad y análisis de estilo nos pareció pertinente a partir de pistas encontradas en la reflexión del propio Mitchell, cuando afirma que el objetivo de comprender la relación imagen/texto:

[...] no es detenerse en la descripción formal, sino preguntarse cuál puede ser la función de las formas específicas de heterogeneidad. Tanto las preguntas formales como las funcionales requieren respuestas históricas: no están predeterminadas por ninguna ciencia universal de los signos y su relación con un "concepto de periodo" histórico es discutible. (Mitchell, 2009, p. 93)

Como Butler argumenta, el análisis del estilo también se preocupa por la función y, como Mitchell, él también considera que el lugar más apropiado para proceder a un análisis de la heterogeneidad formal de una representación es la representación misma. Creemos que hablar de función contribuye al entendimiento de que la relación imagen/texto es el locus de un conflicto, los nexos en los cuales entran en juego antagonismos políticos, institucionales y sociales en la materialidad de la representación.

En el análisis aquí presentado daremos dos de los cuatro pasos desarrollados por Butler: el análisis descriptivo y el análisis funcional. ${ }^{6}$ La descripción sería lo

6 El análisis histórico dependería de una retrospectiva en los programas del género a fin de identificar patrones. El análisis valorativo hasta el mismo Butler lo entiende como problemático por la falta de parámetros más específico para juzgar la estética televisiva. 
que el autor llama "de paso básico" y todos los estudios de medios que se dedican al estilo deben desarrollar un método de descripción de la "superficie de percepción" (Bordwell, 2008) de una obra. Es necesario, entonces, buscar la esencia del estilo en los detalles de la transmisión de sonido e imagen, siendo precisa una "ingeniería invertida" de los textos, para que podamos comprender plenamente su estilo. Así, la misma atención al detalle que guionistas, directores y demás profesionales dedican a la construcción de un texto televisivo debe ser empleada en su deconstrucción. La descripción de un programa no debe replicarlo. Debe servir para promover el análisis.

El análisis funcional, basado en "la teoría funcional del estilo en el cine" de Naol Carrol (2003), pretende detectar los propósitos del estilo y sus funciones en el texto. Al hacerlo, el analista examina el funcionamiento del estilo dentro del sistema textual, buscando patrones de elementos estilísticos y, en un nivel más elevado, las relaciones entre los mismos patrones. Usando estilo y forma de manera intercambiable, Carrol afirma,

El abordaje descriptivo dice que la forma fílmica es el conjunto total de todas las relaciones entre los elementos de la película. La funcional dice que la forma fílmica incluye apenas los elementos y relaciones intencionales para servir como medio para el propósito del filme. (2003, p. 141)

Butler apunta varias funciones del estilo televisivo. Las cuatro primeras fueron heredadas del cine y las demás las desarrolla para aquel medium de modo específico. Son denotar, expresar, simbolizar, decorar, persuadir, llamar o interpelar, diferenciar y significar "en vivo".

\section{Unidad de análisis: la edición del evento narrativo}

En el caso de narrativas de ficción, una de las dificultades en el trabajo con narrativas de ficción tiene que ver con el significativo volumen del material en cuestión. En este sentido, las unidades de análisis no siempre son precisas y con frecuencia lo que los autores adoptan son fragmentos (como escenas) de una narrativa. Aunque es difícil, estamos convencidos de que la visión del conjunto sería más productiva para la cuestión señalada en este texto y, por lo tanto, optamos por adoptar lo que llamamos "eventos narrativos" como forma de introducirnos en el material. Estos eventos componen una trama (o subtrama) y podrían ser traducidos como los acontecimientos, las acciones que garantizan el desarrollo de la historia -tales como bodas, romances, las negociaciones empresariales, traiciones, disputas de poder, etc.-, que pueden o no durar varios capítulos. Seguirlos permite al analista ver el entrelazamiento de las tramas, el uso de indicadores temporales precisos y la inserción de causas pendientes para la articulación adecuada de las secuencias separadas temporalmente. 


\section{Análisis cultural}

La importancia cultural de la televisión ya cuenta con un repertorio significativo de investigaciones que muestran la relevancia de este medium en varios aspectos (França, 2006; Martín-Barbero, 2001; Martín-Barbero \& Muñoz, 1992). Compartimos las premisas de esos análisis y tenemos interés en ampliarlos en la medida en que entendemos que la noción de visualidad colabora con la identificación de los regímenes vigentes en un contexto sociohistórico dado. En la articulación entre formas de ver y mostrar y en el tratamiento formal y narrativo dado a las temáticas abordadas en producciones televisivas es donde creemos posible la captación de dichos regímenes. La televisualidad es un constructo relevante en la medida en que nos conduce a los modos en que los textos televisivos muestran las cuestiones tejidas y vividas en el terreno de la política y la cultura. La televisualidad nos lleva a ver lo que está fuera del texto, a partir del análisis de lo que está en su interior. Nos advierte a "dudar" de las pictures, para exigir de esas materialidades, de manera que podamos percibir los cruces y lo que debe ser "sacudido" en los procesos de familiaridad y naturalización.

Así retomamos a Brea (2005), para quien es necesario desuniversalizar los modelos de regímenes del ver, poner en su contexto histórico las condiciones sociales de lo visible, tanto en relación con el tiempo en el que esos regímenes fueron construidos, como en relación con las diferencias culturales que pueden revelar diferentes modos de socialización también específica (en Uruguay, por ejemplo, tal retórica de la prohibición ya no tiene el mismo sentido). Uno de los puntos que parece relevante en este edificio analítico es la contribución a una epistemología local que ofrezca las bases para un entendimiento más amplio del producto objeto de análisis.

\section{Televisualidades y sistemas visuales}

Con la discutido hasta ahora, es posible afirmar que, desde nuestra perspectiva, es más pertinente hablar de regímenes de visualidad, justo así, en plural. Si la televisión es un medio en profundo diálogo con su contexto de producción y consumo, el investigador precisa estar atento a los diferentes regímenes que puede generar esa mutua afectación. Esto nos permite pensar también que este camino de análisis nos ayudará a entender cómo los productos televisivos corroboran ciertos regímenes, revelando qué estado de discusión acerca de una temática es el que gana en un contexto determinado e identificando en qué medida ciertas narrativas rompen con regímenes compartidos de forma hegemónica.

Esto abre el camino al análisis de otras dimensiones que componen el circuito de la televisión pues, cuando se entiende que determinado producto rompe con formas consagradas de ver y mostrar, el investigador se sentirá interpelado a 
investigar, por ejemplo, los modos de producción de este producto, las mediaciones y los fundamentos políticos y económicos en juego en ese proceso.

Nos gustaría, apenas como ejemplo, citar dos investigaciones en curso en el marco de nuestro grupo de investigación, con el fin de mostrar cómo esta propuesta metodológica ha influido en los trabajos desarrollados actualmente. Hacemos hincapié en que no fue nuestro propósito presentar un análisis profundo del asunto, ya que nuestras investigaciones apenas comienzan. Lo que pretendimos fue tan solo evidenciar las posibilidades teórico-metodológicas de la noción de visualidad.

\section{8. "Él es el atraso y usted, la modernidad"}

El primer ejemplo surge del análisis de un evento narrativo extraído de la telenovela Dos Caras (TV Globo, 2007), que trata sobre el proceso de candidatura a concejal de Evilásio Caó (Lázaro Ramos), pese a la insatisfacción de su padrino Juvenal Antena (Antônio Fagundes), líder comunitario, autoritario, temido y admirado. Antena dirige la Favela da Portelinha con mano de hierro, de acuerdo con sus propios valores, cree que cuida a su pueblo y actúa como el gran proveedor de la favela. Juvenal cuenta con hombres de confianza -los siete enanos- que lo ayudan a dirigir la Portelinha. Entre ellos se encuentra Evilásio Caó, su ahijado, con quien tiene un fuerte lazo afectivo, pero que discrepa con su padrino, principalmente, a causa de su autoritarismo y su abuso de poder en el liderazgo de la comunidad. Como represalia, el líder de la favela lanza su candidatura para enfrentarse a su ahijado, iniciando un conflicto que muestra las contradicciones y enfrentamientos entre una posición autoritaria, mandona y opresora, y otra más liberal, dispuesta al diálogo y la acción política dentro de la ley y los preceptos democráticos.

Durante el evento, notamos un intento de colocar a Juvenal y a Evilásio en posiciones características de lo que es propio de lo arcaico y de lo moderno, de manera que la postura del segundo sugiere que la democracia y el diálogo serían los principios más relevantes. Entendemos ese evidente antagonismo como un recurso narrativo adoptado para demostrar con más claridad las matrices subyacentes, que después serán combinadas y articuladas en la secuencia final del evento. Tales posiciones se evidencian en una conversación entre Evilásio y su esposa, Julia, cuando el joven considera desistir de la candidatura, pues no consigue luchar contra el padrino en su "territorio". Evilásio llora y el tema músical es triste.

Júlia: Evilásio, o que que foi? Evilásio, você está chorando por quê?

Evilásio: Júlia, eu não me conformo. Deu tudo errado. Eu não queria brigar assim com meu padrinho. Ainda mais enfrentar ele desse jeito, de palanque para palanque. Eu 
só queria fazer com que ele entendesse que a Portelinha não pode continuar sendo o "reino" dele.

Júlia: É, Evilásio, só que ele não entendeu e vocês romperam por causa disso e agora fazem oposição um ao outro. Evilásio, Ele é o atraso e você, a modernidade [...]. E a modernidade sempre acaba vencendo o atraso, viu? E aqui na Portelinha vai ser assim também [...] [extracto tomado del capítulo $\mathrm{n}^{\circ} 174$ ].

El antagonismo entre el atraso y lo moderno también se muestra en la dimensión audiovisual de la telenovela, especialmente, a través de la música y el encuadre de los personajes. En una secuencia que comienza con Evilásio distribuyendo panfletos de campaña y presentando sus propuestas, la música de fondo (playback) es Gato Negro, de Roberto Carlos y Erasmo Carlos, cantada por Mc Leozinho.?

Figura 1. Encuadre de Evilásio sugiriendo visualmente una postura dialógica. ${ }^{8}$

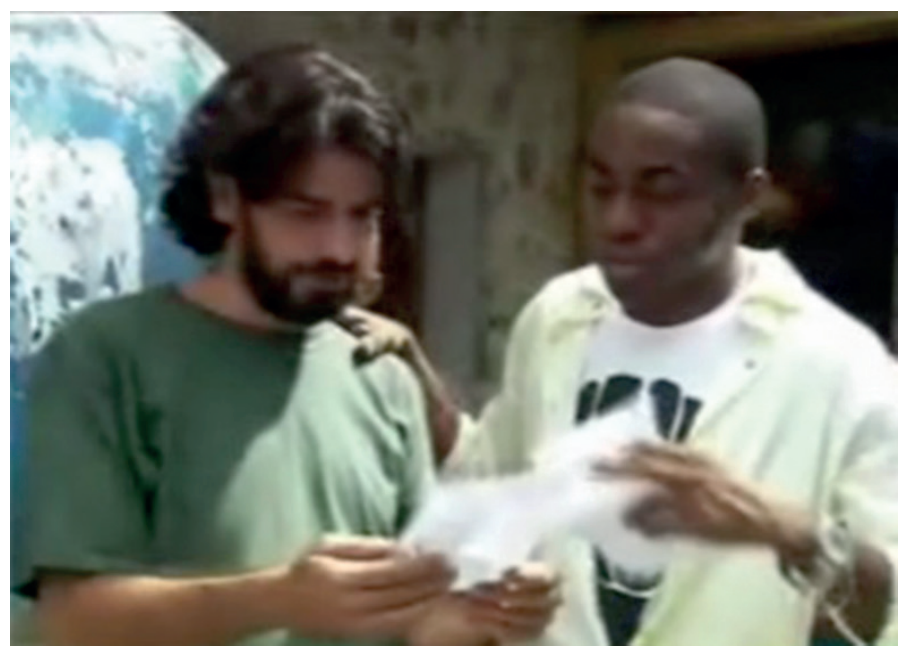

En esos momentos, Evilásio es encuadrado en una de las esquinas de la pantalla en el plano medio (PM) como sugerencia visual de una postura dialógica, igualitaria en relación con los demás ocupantes del plano (figura 1). Durante uno de sus abordajes, el joven es interrumpido por Juvenal, encuadrado en el centro de un plano de conjunto (PC), rodeado de sus siete enanos (figura 2). El líder de Portelinha afirma que aquel es un territorio neutral en el que no se puede hacer campaña. Continúa el mismo playback mientras Evilásio responde a la posición de Juvenal, que le ordena salir de allí: “[...] recoge esa papelada y vaya

7 Que adaptó la melodía incluyendo toques de funk.

8 Las imágenes de la telenovela Dos caras fueron obtenidas de páginas de internet y contienen el logo de la emisora a la que pertenecen. 
a distribuirla a otros parroquianos", a lo que Caó replica: "me disculpa, pero yo soy residente de la comunidad y aquí estoy hablando con mis vecinos y nadie lo va impedir". En este momento un tema musical con acordes aislados de piano da cuenta de una situación de confrontación y ayuda a narrar la secuencia, mostrando un embate entre posiciones antagónicas. Junto al tema sonoro, el encuadre de los personajes hace hincapié en la tensión, a la vez que ambos aparecen solos en el centro de la pantalla, en primer plano (PP). Mientras el conflicto persiste, Juvenal permanece en el centro de todo el plano y Evilásio vuelve a aparecer en los extremos acompañado de los residentes.

Figura 2. Juvenal es encuadrado en el centro de un plano de conjunto, rodeado por sus siete enanos.

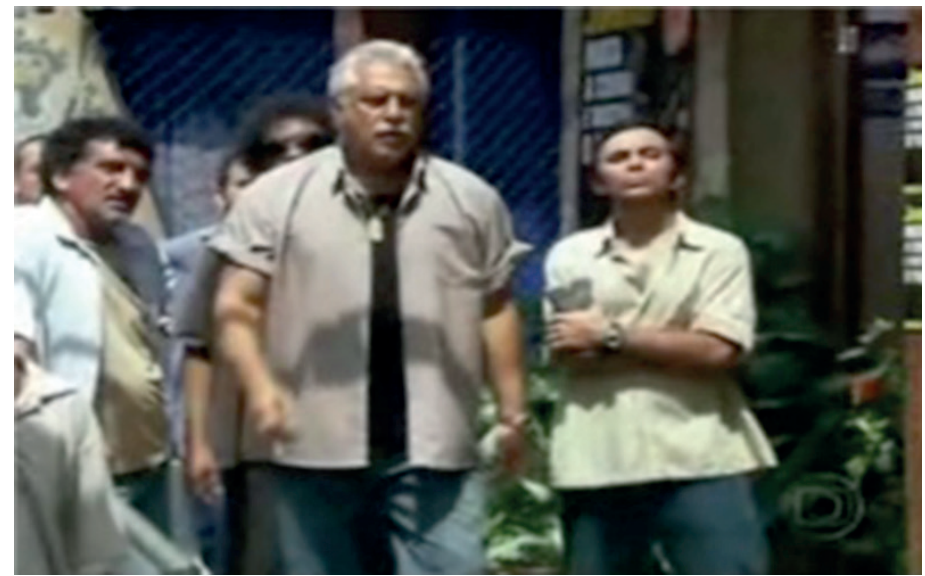

La secuencia también trae otras demostraciones de estas posiciones siguiendo este patrón de representación visual: Evilásio abordando a las personas, presentando propuestas, y Juvenal intimidando, amedrentando y exigiendo fidelidad -en una especie de figuración del voto de cabestro, ${ }^{9} \mathrm{de}$ las relaciones clientelistas-,$^{10}$ ambos acompañados de los temas musicales ya mencionados.

En el momento final del evento narrativo, Evilásio aún se muestra incómodo por llevar adelante su candidatura sin el apoyo del padrino. En varios momentos demuestra dudas, deseos de desistir porque no se siente cómodo frente al padre de Portelinha. A partir de ese recelo de Evilásio se hacen evidentes las dimensiones del poder de Juvenal, que remiten a las estructuras tradicionales

9 Sistema de control político que se vale del abuso de poder, la compra de votos y el uso de las instituciones públicas. Es característico del "coronelismo" brasileño y aún pervive en algunas regiones pobres de Brasil. 10 El clientelismo se puede definir como "una especie de relación entre actores políticos que implica la concesión de beneficios públicos en forma de puestos de trabajo, beneficios fiscales, exenciones, a cambio de apoyo político, especialmente en forma de votos" (Carvalho, 1997). 
del caudillismo. Victor Nunes Leal argumenta que el coronel (una especie de mandón) ejerce "una amplia jurisdicción sobre sus dependientes, provocando riñas y desavenencias y profiriendo, en ocasiones, verdaderos arbitrajes, que los interesados respetan" (Leal, 2012, p. 47). La estructura social creada por el mandonismo permite al mandón controlar al pueblo, la economía y las instituciones sociales, lo que le da prestigio y dominio político. Él detenta el poder y designa quien puede compartirlo con él. El mandón es adorado, pues concede favores a su pueblo. De esa forma, es posible comprender el dilema de Evilásio y la importancia del apoyo de Juvenal. Esto se explica tanto por la relación de afecto como por la legitimidad de su candidatura, a partir del respaldo que solo Juvenal puede ofrecer.

Esa última secuencia comienza con Julia preocupada, pues sabe que su marido fue llamado a una conversación con Juvenal Antena. Los tres primeros minutos del diálogo son del mandón enfrentándose a Evilásio, debido a los resultados de las últimas investigaciones, en las que el joven no aparece bien parado en las intenciones de voto. Juvenal pregunta si el ahijado realmente tenía alguna expectativa de ganar sin su apoyo. De nuevo, encuadre y música muestran el conflicto. La conversación se construye en planos y contra-planos, en un montaje que denota enfrentamiento. La tensión es mostrada por la música, en momentos clave, con acordes que evocan suspense. Juvenal sigue exigiendo fidelidad:

Juvenal: Tudo o que tu sabes fui eu quem te ensinei. E o que que tu fez em troca? Me traiu. Quis ocupar o meu lugar. Se voltou contra mim.

Evilásio: Eu não me voltei contra você. Eu discordei de você. Coisa que Juvenal Antena não admite. Discordei e discordo. Discordo da maneira que o senhor faz e acontece na Portelinha. O senhor aprisiona as pessoas, mesmo quando ajuda. Discordo dos seus métodos, discordo de tudo que o senhor representa [extracto tomado del capítulo $\left.n^{\circ} 197\right]$.

La conversación continúa en ese tono mientras Juvenal refuerza su capacidad de controlar todo y a todos. Evilásio resiste y afirma que no va a cambiar su forma de pensar. Es en este momento cuando Juvenal afirma que "la banda continuará tocando a mi manera" y propone un acuerdo: retirar su candidatura, le dice a la gente que vote por el ahijado y continúa mandando en la Portelinha. Por otro lado, Evilásio representa a la comunidad en el ayuntamiento y pasa a "luchar para el pueblo." Al percibir que le estaba proponiendo una alianza, Evilásio reacciona: "Pero voy a actuar de acuerdo con lo que yo creo", a lo que Juvenal responde: "Está bien, vamos a encontrar un camino intermedio". Los dos sellan la alianza y el joven se muestra aliviado y abraza al padrino, que lo acoge como un padre que abraza un hijo con una postura protectora (figura 3 ). 
Figura 3. Juvenal abraza Evilásio depués de sellar la alianza.

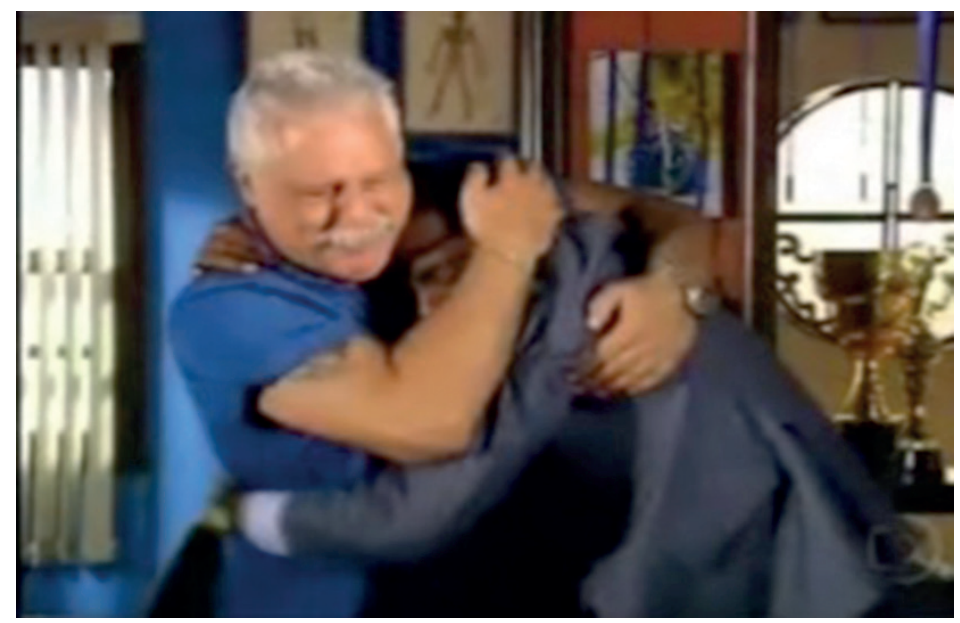

Lo que se desprende del análisis del evento son dos estilos diferentes de hacer política que, en principio, entran en choque y terminan con una forma de acomodamiento construido sobre la base de la negociación: Juvenal propone una alianza y ambos se unen en pro de la candidatura de Evilásio, en una clara demostración de la conjugación de las distintas matrices que componen nuestra cultura política. Las escenas con closes en apretones de manos, del padrino y del ahijado en posiciones diferenciadas dentro del plano (figuras 1 y 2), acompañados de temas musicales cuidadosamente elegidos, nos muestran que la televisualidad del evento, es decir aquello que, dentro de cierto régimen de lo visible fue dado a ver, evidencia dos formas de hacer política en la vida cotidiana -una remitiría a lo arcaico y otra expresaría lo moderno- que solo existen en la articulación de la una con la otra. Cuando son colocados en escena, primero en situación de conflicto, posteriormente unidos por una alianza afectivo-política, demuestran la forma en la que las matrices culturales, específicamente lo arcaico/moderno, se mezclan y así constituyen nuestra modernidad periférica (Herlinghaus \& Walter, 1994) y subyacen las relaciones sociopolíticas.

Estos modos de caracterizar cierta cultura política, reiteran la televisión como un lugar privilegiado para percibir nuestra realidad cultural, constituida por contradicciones. Son ellos los que configuran nuestro contexto moderno, en el que el hibridismo se sitúa como un rasgo histórico de nuestra modernidad y produce diferentes formas de interculturalidad. 


\section{Todo lo que quería en esta vida, era solo un pedacito de tierra ${ }^{11}$}

La segunda investigación en curso parte de la constatación de que la tierra, además de presentarse como un tema transversal en la teledramaturgia de Benedito Rui Barbosa, se erige como narrador-personaje en la poética televisual. Esa condición de narrador-personaje revela rasgos de omnisciencia, porque hay saberes provenientes de la tierra en la expresión de la cultura popular; y rasgos de omnipresencia, pues el elemento tierra cuando no está presente visualmente, está en las conversaciones de los personajes, en sus demandas, preguntas y preocupaciones. A partir de la pregunta de investigación, “qué matriz cultural emerge y sustenta la tematización de la tierra en su aspecto televisivo?", se seleccionaron un total de cinco telenovelas de este autor y, dentro de cada una de ellas, un evento narrativo para proceder al análisis y tratar de identificar y reflexionar sobre lo que está fuera del texto y que, al mismo tiempo, está presente bajo la forma de esta concepción matricial que subyace a toda la trama.

El evento narrativo presentado ahora es el diálogo entre los personajes Tião Galinha (Osmar Prado) y el padre Lívio (Jackson Costa) de la telenovela Renacer (TV Globo, 1993). Tião es un antiguo cazador de cangrejos en un manglar, que se muda con la familia a la zona del cacao con la esperanza de una vida mejor. A esa altura de la trama, después de sucesivas humillaciones, el matuto ${ }^{12}$ está desempleado y desesperanzado. En un gesto desesperado confiesa al progresista Padre Lívio su intención de invadir y disputar tierras, ya que no tiene los recursos para comprar. El sacerdote intenta hacerlo cambiar de idea.

En los primeros 11 segundos de la secuencia, la cámara enfoca la copa de una palmera en un movimiento circular, en sentido antihorario, seguido por un tilt hasta ajustarse, a los 12 segundos, al nivel del suelo haciendo una panorámica (PAN) encuadrando al padre, en plano abierto (plano de ubicación). Se trataría tan solo de una toma de transición en relación con la escena anterior de la telenovela, lo que incluye el background (BG) -si no fuera por el hecho de que la mayor parte de la conversación es filmada por una cámara en movimiento circular-. El diálogo entre Tião y el Padre Livio podría haberse filmado mediante el tradicional esquema de plano y contraplano común en las telenovelas. Al parecer, la dirección optó por el plano secuencia y los movimientos circulares con la cámara en mano en sentido horario. Cada giro se sincroniza con la respuesta de cada personaje, pues el movimiento circular del plano secuencia hace que, en cada giro, uno de los personajes en el cuadro aparezca en un plano frontal medio (que es un plano de posicionamiento y movimiento), en plano americano (PA), en el primer plano medio (MPP), de perfil, en plano de nuca, picado y contrapicado.

11 Agradezco a Reinaldo Maximiano Pereira la colaboración prestada en esta sección.

12 Se refiere a la persona que vive en el monte o en el campo. También puede describir a alguien ignorante o ingenuo. 
Puede pensarse que ese girar alrededor de un eje es significativo porque demuestra que todo el diálogo que sigue será en torno a la propiedad de la tierra. Por otra parte, el movimiento dextrógiro puede simbolizar la acción del tiempo, es decir, simboliza que el tema está en debate dentro de la agenda política, que las acciones lo circundan pero no lo resuelven. En otros términos, es como si diésemos vueltas alrededor del problema sin tocar el centro de la cuestión de una manera efectiva y eficaz.

Figura 4. La cámara realiza un movimiento circular siguiendo la copa del palmera, después un tilt down y el eje se ajusta en la horizontal con el Padre Livio. En plano abierto se inicia un travelling y luego un plano secuencia a medida que el sacerdote se acerca a su interlocutor, Tião, el fondo del cuadro. ${ }^{13}$
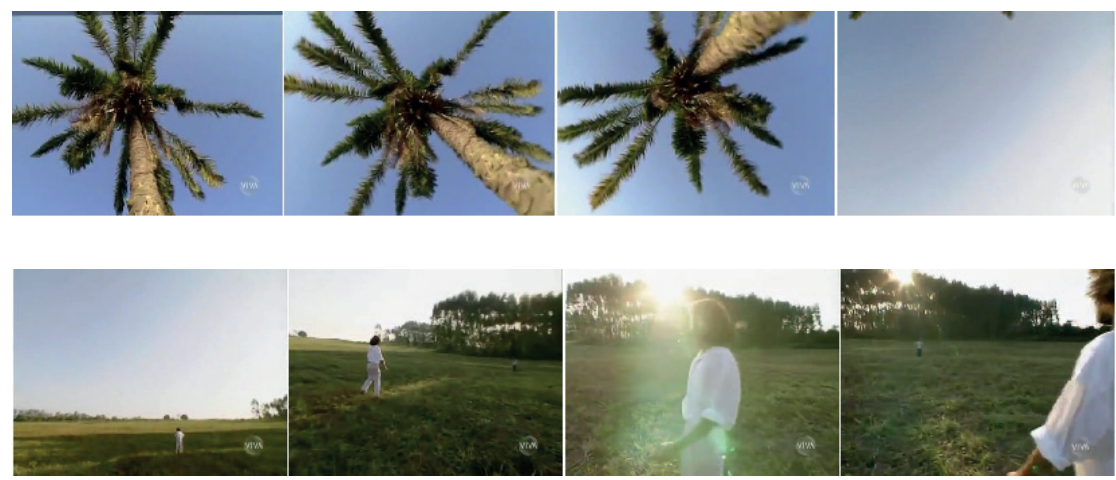

Otro elemento que debe destacarse en esta secuencia habla del modo en que la cámara se encuentra lejos de la figura humana, que ocupa una diminuta porción en el eje dramático. Después de ajustar el eje para un movimiento en horizontal (a la derecha del cuadro), se inicia un travelling hacia adelante, aún en plano abierto, seguido de un plano secuencia que acompaña el caminar del sacerdote hacia Tião (figura 4). Después de 24, segundos, Tião es encuadrado en un plano general (PG), que también revela el escenario en gran proporción. Esto nos hace creer que cuando Tião pregunta por la falta de tierras, la dimensión de la visualidad muestra que el problema no es precisamente ese. Tierra hay y mucha. Basta ver lo pequeños que nos volvemos ante tamaña inmensidad. Sin embargo, para entender el quid del problema, la cámara se acerca a los personajes (figura 5) para que Tião nos explique cuál es el verdadero motivo: mala distribución, un problema que se remonta a los tiempos de las Capitanías Hereditarias y las formas desiguales de distribución de la tierra en Brasil y en poder de quiénes se encuentra el derecho de posesión.

13 Las imágenes de la telenovela Renacer fueron obtenidas de la web de Globosat/VIVA y traen el logo de la emisora a la que pertenecen. 
Figura 5. La cámara se acerca a los personajes para acompañar sus reflexiones sobre el tema de la tierra
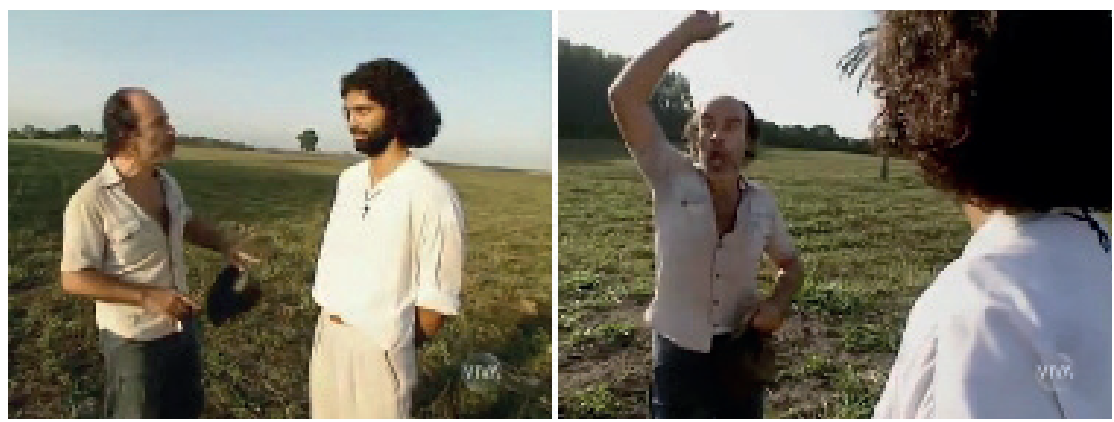

Ese recurso de posicionar al ser humano en una dimensión menor respecto al escenario, realza la presencia del tema de la tierra en las obras de Barbosa, ya sea -creemos- a través de su fuerza visual, ambientación, situación o personaje. El diálogo es el siguiente:

Pe. Lívio: Olha, Tião, pel’amor de Deus, Tião, pára com essa bobagem de querer disputar terra, Tião! Pelo amor de Deus, tira isso da sua cabeça, que você só vai poder disputar terra, nesse país, é com índio, lá no Pará, lá no Amazonas. Porque o resto, já ta tudo tomado, Tião! Isso aqui tudo já tem dono, já!

Tião: Pe. Lívio, Deus quando fez o mundo, não deu terra pra ninguém! Por causa de quê que tem tanto dono, né memo? Quem foi que deu terra pra eles, me diga? Porque o sinhô é o ministro de Deus na terra. Foi Deus? Foi Ele que deu? E se Ele deu, Ele deu de papel passado? [extracto tomado del capítulo $\mathrm{n}^{\circ} 101$ ].

El debate entre el Padre Livio y Tião, en términos del análisis cultural, se construye a partir del sentido de la propiedad y la lógica de distribución de la tierra. Mientras el cura señala cuestiones políticas e ideológicas, Tião intenta darle un sentido fundamentalmente místico. En Brasil, las políticas de reforma agraria están caracterizadas como un largo proceso de lucha contra la concentración de grandes extensiones de tierra y contra la exclusión de los trabajadores agrícolas al acceso a las políticas sociales en materia de derechos laborales (García Jr., 1983).

La posición de los actores en escena también es cambiante, en el eje dramático: el diálogo comienza con los personajes separados en el campo, en PG, se acercan, en la medida en que parecen llegar a un punto de acuerdo, y se alejan en momentos de desacuerdo y/o duda. Por ejemplo, en 37 segundos, durante el travelling hacia adelante, Tião es encuadrado en PG, la cámara se acerca a ras de suelo, a lo largo del parlamento del personaje, y continúa en un plano frontal medio (que es un plano de posición y movimiento), PA, medio primer 
plano (MPP), perfil, nuca hasta que Tião sale del cuadro y vemos a Livio en un plano abierto, después de PM, PA, MPP, el perfil, nuca y perfil, nuevamente. En un segundo movimiento, Tião es encuadrado en un plano picado. Más tarde, ambos son encuadrados en PA, como se ve en la figura 6:

Figura 6. Alternancia de planos de encuadre, a partir de un movimiento circular.

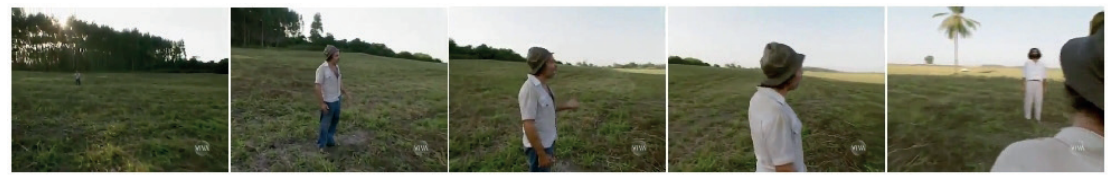

El diálogo entre los personajes es el siguiente:

Tião: Pe. Lívio, Pe. Lívio, foi Deus que fez isso tudo, não foi? [abre os braços] Pe. Lívio: Foi, foi Deus, sim!

Tião: E a Sagrada Escritura, é a escritura da terra?

Pe. Lívio: Mas que besteira você está falando. Que Sagrada Escritura é escritura de terra o quê? Onde foi que você ouviu isso? [extracto tomado del capítulo $n^{\circ} 101$ ].

Tanto los movimientos de cámara como los encuadres y las posiciones de los actores en escena fluyen de acuerdo con el comportamiento de cada personaje y los subtemas que son tratados a partir del tema central del diálogo, o que circundan ese tema. Cuando la secuencia se acerca a su fin, Tião pasa a ser encuadrado en picado (figura 7), ante un padre constreñido, y hace su confesión como si estuviese frente a Cristo:

Figura 7. Del encuadre en PA al encuadre de nuca que enfoca a Tião en picado.
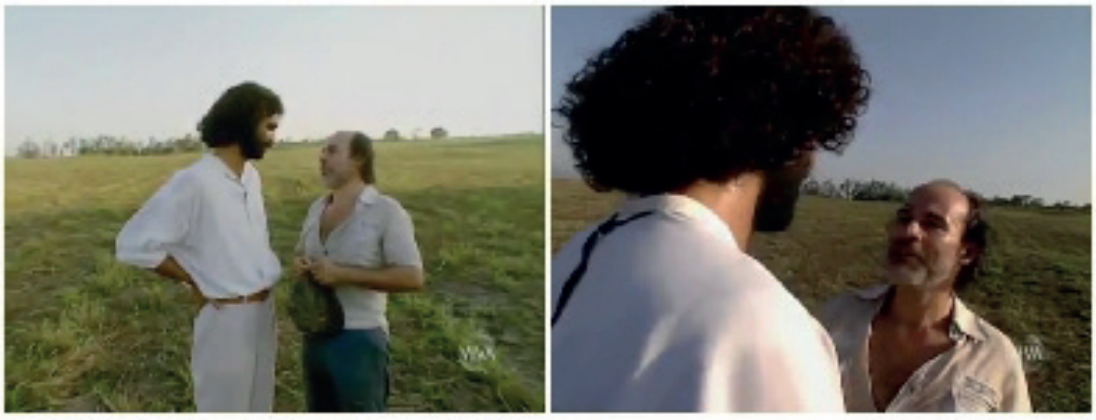

Tião: Eu posso dizer uma coisa pro sinhô, de coração? Tudo que queria nessa vida, era só um cadim de terra. Assim, olha, um bocadinho só. Uma coisinha pequenininha. Não ia fazer falta para quem tem, não. O sinhô me entende? 
Pe. Lívio: Entendo, sim, esse é o problema de muita gente [extracto tomado del capítulo $\left.n^{\circ} 101\right]$.

Así las cosas, el diálogo, en una trayectoria circular, tal como es ilustrado en la dimensión de la televisualidad, se cierra en el punto en el que comenzó: ¿por qué pocos son dueños de tanta tierra y muchos ni tan siquiera un pedacito? Tião entra y sale de escena sin tierra y sin respuestas.

\section{Comentarios finales}

Nuestra preocupación al diseñar una investigación acerca de la televisión que no perdiese de vista su complejidad nos ha llevado a la propuesta de los visual studies, debido a su apertura teórica y metodológica, así como a la historicidad y al contexto de producción de las pictures a los que tal perspectiva permite. Este esfuerzo de investigación, que tiene como base fundamental la noción de televisualidad, puede también enfocarse desde la perspectiva de la semiótica de la cultura, ya que el concepto de visualidad podría entenderse como "visión socializada" (Abril, 2012), o sea, como un proceso social en el cual se articulan discursos, ideologías, significantes y deseos, entre otros; diferentes experiencias del mirar que explicitan y posibilitan reflexionar sobre las articulaciones entre textos visuales, sujetos, tiempos y espacios sociales.

Pensar esa "visión socializada" nos ayuda a comprender que las imágenes visuales no se agotan en lo visible, sino que están ancladas en dimensiones invisibles que sustentan el propio gesto de mostrar, pues "vemos a través de los ojos de nuestra cultura, de los sistemas simbólicos, conocimientos, valores y estereotipos adquiridos por medio de la inculturación" (Abril, 2012, p. 23). El campo de estudios de la cultura visual puede ser definido como el estudio de las construcciones culturales de la experiencia visual cotidiana, así como, en los medios de comunicación, las representaciones y las artes visuales, cuyo foco es el análisis de la imagen visual como un elemento de los procesos de producción de significado en los contextos culturales.

\section{Referencias bibliográficas}

Abril, G. (2012). Tres dimensiones del texto y de la cultura visual. IC-Revista Científica de Información y Comunicación, $\mathrm{n}^{\circ}$ 9. Sevilla.

Barnard, M. (2001). Approaches to understanding visual culture. Nueva York: Palgrave.

Bordwell, D. (2008). Figuras traçadas na luz. Campinas: Papirus.

Brea, J. L. (2005). Estudios Visuales: La epistemología de la visualidad en la era de la globalización. Madrid: Akal Estudios Visuales. 
Butler, J. (2010). Television Style. Nueva York: Routledge.

Carvalho, J. M. (1997). Mandonismo, Coronelismo, Clientelismo: Uma Discussão Conceitual. Dados: Revista de Ciências Sociais, v. 40 (2), Río de Janeiro. Recuperado de: http://dx.doi.org/10.15.90/Soo11-525819.97000200003.

França, V. (2009). A televisão porosa. Traços e tendências. En: Freire Filho, J. (ed.). A TV em transição. Porto Alegre: Sulina (pp. 27-52).

García Jr., A. R. (1983). Terra de trabalho: trabalho familiar de pequenos produtores. Río de Janeiro: Paz e Terra.

Guasch, A. M. (2003). Los estudios visuales, un estado de la cuestión. Estudios Visuales, $\mathrm{n}^{\mathrm{0}} 1$.

Herlinghaus, H. y Walter, M. (1994). ¿”Modernidad periférica” versus "proyecto de la modernidad"? Experiencias epistemológicas para reformulación de lo 'pos' moderno desde América Latina. En Hermann Herlinghaus y Monika Walter (eds.).: Posmodernidad en la periferia: enfoques latino-americanos de la nueva teoría cultural. Berlín: Langer.

Knauss, P. O. (2006). Desafio de fazer História com imagens: arte e cultura visual. ArtCultura, Uberlândia, v.8, $\mathrm{n}^{\mathrm{o}} 12$, jan-jul.

Leal, V. N. (2012). Coronelismo, enxada e voto: o município e o regime representativo no Brasil. São Paulo: Companhia das Letras.

Martín-Barbero, J. (2001). Dos meios às mediações. RJ: EDUFRJ.

Martín-Barbero, J. y Muñoz, S. (1992). Televisión y Melodrama. Bogotá: Tercer Mundo Editores.

Mitchell, W. J. T. (1994). Picture Theory. Londres: The University of Chicago Press.

Mitchell, W. J. T. (2005). What the pictures want? Londres: The University of Chicago.

\section{Referencias Audiovisuales}

Ruy Barbosa, B. (escritor) y Carvalho, L. F. (director). (1993). Renacer [telenovela]. 216 capítulos. Río de Janeiro.

Silva, A. (escritor) y Maia, W. (director). (2007). Duas Caras [telenovela] 210 capítulos. TV Globo. Río de Janeiro. 